\title{
Phytochemical and Biological Studies on Usnea Orientalis and Rhododendron Campanulatum of Nepal
}

\author{
Sushika Joshi (Mulmi)* and Pradip Bastola \\ Central Department of Chemistry, Tribhuvan University, Kirtipur, Kathmandu, Nepal \\ Email: sushikajoshi@gmail.com
}

\begin{abstract}
Phytochemical and biological screening of Usnea orientalis and Rhododendron campanulatum were carried out. The brine shrimp bioassay showed that the ethereal and methanolic extract of Usnea orientalis and the methanolic extract of Rhododendron campanulatum were biologically active. Antibacterial susceptibility studies of various extracts showed that the ethereal extract of Usnea orientalis and methanolic extract of Rhododendron campanulatum have antibacterial properties towards both gram positive and gram negative bacteria. Two major constituents usnic acid and diffractaic acid from the ethereal extract of Usnea orientalis have been isolated and identified by their melting points, Co-TLC| and 1H-NMR spectra comparison with authentic samples. The other two compounds viz. atranorin and eumitrin have been identified by Co-TLC and melting points comparison with the authentic samples. Diffractaic acid was isolated from Usnea orientalis. Usnic acid showed inhibition towards gram positive bacteria i.e. S. aureus. The brine shrimp bioassay of pure isolated compounds showed that usnic acid, diffractaic acid and atranorin were biologically and pharmacologically active.
\end{abstract}

\section{Introduction}

Usnea Orientalis is a type of lichen plants which belongs to Usneaceae family. It grows on bark of twigs of trees like Rhodendron, Castanopsis etc. Lichen as pollution indicator of sulphur dioxide, heavy metals and radioactive metals. These substances are absorbed by lichen from the air very rapidly and accumulate inside the thallus which causes the death of lichen. Thus amount of lichen available in an area indicates the level of environmental pollution of that area.

Lichen is one of the economic plants of Nepal as it can be used in different medicinal and other purposes. Usnic acid obtained from different lichens is used as antibiotic like penicillin ${ }^{1,2}$. Likewise, Parmelia species is used to treat epilepsy. Lobaria (lungwort) is used to treat TB and Lung Cancer. Cladonia is used to treat whooping cough. Peltigera for hydrophobia, Certraria for diabetes,etc. Usnea spps are used in dyes, cosmetics and medicines. Certraria juniperina and Letharia vulpina (wolfmoss) are used as poisons. The sea lichens are used for food and fodder eg. Cladonia (Reindeermoss) in artic regions and Certeria (Iceland moss) in Iceland ${ }^{3}$.

Collection and taxonomy of lichens from various parts of Nepal have been done by different botanists, however their chemical investigations still need to be carried out. So, this research intends to conduct phytochemical screening and biological and chemical investigation of usnea orientalis and Rhododendron campanulatum.

\section{* Corresponding author}




\section{Experimental part}

\section{Phytochemical study}

\section{Collection of plants materials}

The plants materials Usnea orientalis and Rhododendron campanulatum were collected from Dhankuta district and identified at central herbarium and botanical garden, Godawari. The lichen fragments were made freed from obvious organic substrate materials and species of lichen. The plants materials were dried under shade and powdered500 gm.

\section{Extraction of plants materials}

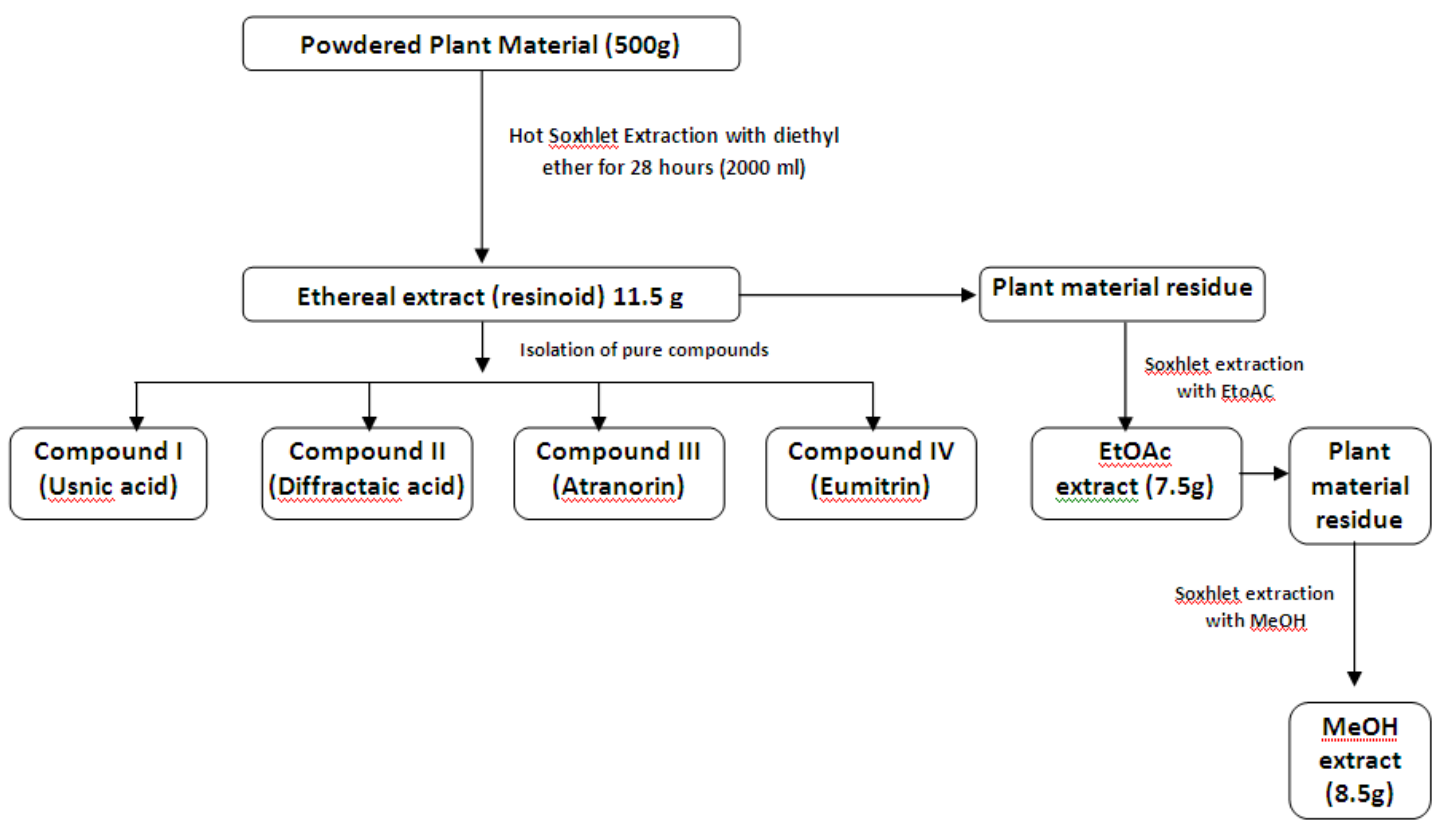

\section{Isolation of plant constituents}

The column (42.5x3.1) was packed with silica gel 100gms 60-120mesh and applied the ether extracts 10.5 gms for chromatography. After loading ether extract, it was eluted sequentially with the solvents of increasing polarity petroleum ether, ethyl acetate and ethanol.

\section{Biological investigations}

- Brine Shrimp bioassay ${ }^{5}$

- Screening of Antimicrobial activities

\section{Results and Discussion}

Four pure compounds were isolated and identified from ethereal extract of Usnea orientalis from Column Chromatography as: 

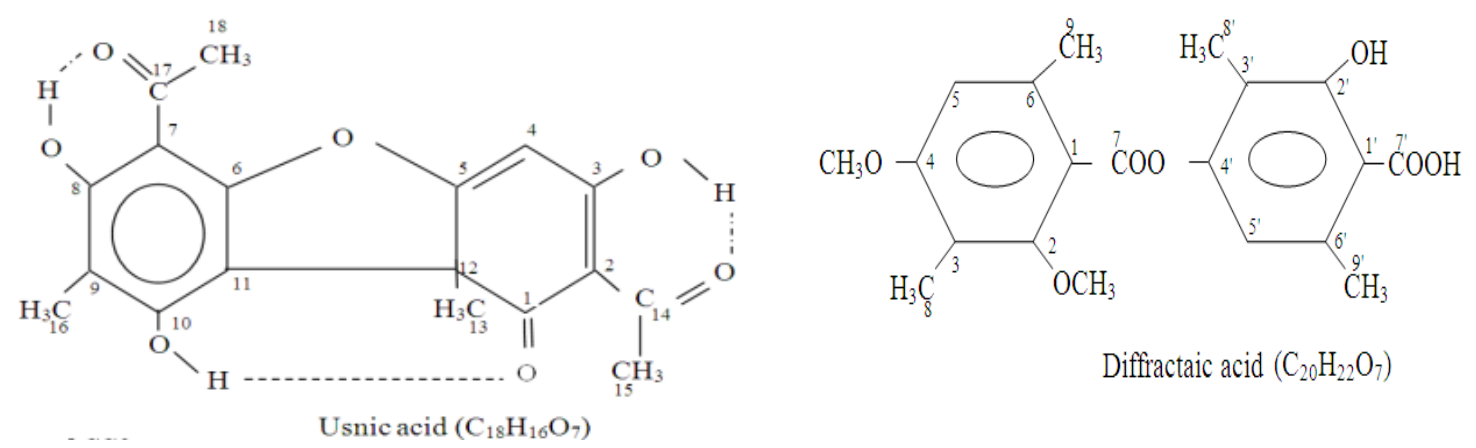

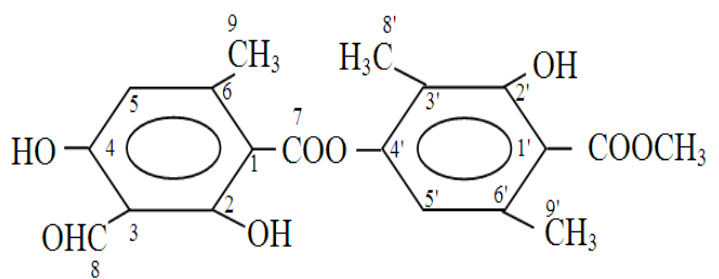

Atranorin $\left(\mathrm{C}_{19} \mathrm{H}_{18} \mathrm{O}_{8}\right)$

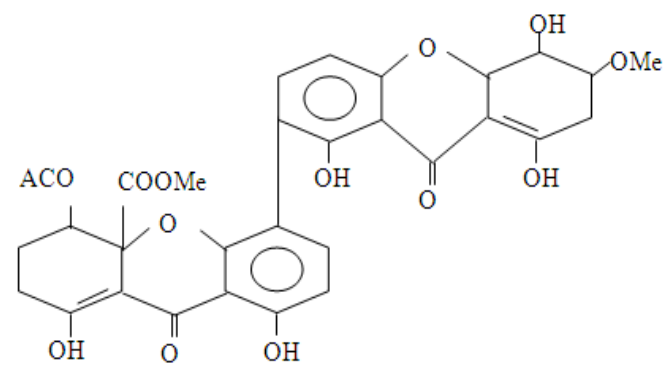

Eumitrin

The yellow needle crystal having melting point of $195^{\circ} \mathrm{C}$ and purple spot under UV light was obtained with 5\% EtOAc in ether from column and its Rf value is 0.56 in $25 \%$ EtOAc in hexane. The ${ }^{1} \mathrm{H}-\mathrm{NMR}$ spectrum of this compound revealed singlet peak at $\square 1.76,2.11,2.66,2.68,5.98,11.04$ and 13.32. The peaks at $11,0,13,3$ and 18,8 were due to phenolic protons. The peaks appeared at 133 was due to $-\mathrm{OH}$ of ring at $\mathrm{C}-8$. The peak at 11.0 is due to proton of $-\mathrm{OH}$ situated at ring. A flanked with ortho- $\mathrm{CH}_{3}$ and $-\mathrm{COCH}_{3}$ group at $\mathrm{C}-10$. On $\mathrm{D}_{2} 0$ shaking only peak at 11.0 and 13.3 remains while at peak 18.8 vanished. Therefore, these two phenolic groups at 11.0 and 13.3 must have involved in hydrogen bonding. These spectra data, Co-TLC and its melting point comparison with authentic sample showed that the compound is Usnic acid ${ }^{6}$.

The white crystalline solid having melting point of $188^{\circ} \mathrm{C}$ was obtained with $10 \%$ EtOAc in ether from column and its $\mathrm{Rf}$ value was 0.52 in $50 \%$ EtOAc. The ${ }^{1} \mathrm{H}-\mathrm{NMR}$ spectrum revealed single peaks at $\square$ $2.165,2.185,2.48,2.61,3.85,3.85,6.54,6.61$. Two single peaks at $2.185,2.165$ were accounted for two methyl groups attached to C-8 and C-8' respectively, whereas singlet peaks at $2.48,2.61$ were due to the methyl groups attached to oxygen atoms at C-9 and C-9'. The singlet peak at $\square 3.85$ showed the presence of -OMe proton at C-2 and C-4 of the compound. The singlet peak at $\square 6.54$ and 6.61 accounted for the presence of aromatic proton (H-5) and (H-5'). This spectrum suggested the compound is diffractaic acid ${ }^{7}$. This was further confirmed by its melting point, Co-TLC and comparison with proton NMR spectral data with of authentic sample.

Fraction $70 \%$ of EtOAc in ether of column gave a colourless substance which was crystallised out from the concentrated solution. The compound was purified by washing with hexane. Its Co-TLC and having melting point of $194^{\circ} \mathrm{C}$ showed the compound is Altranorin ${ }^{8}$.

Fraction $10 \%$ of methanol in EtOAC gave white crystal after washing with hexane. Its melting point and Co TLC showed the compound is Eumitrin ${ }^{1}$. 
J. Nepal Chem. Soc., vol. 30, 2012

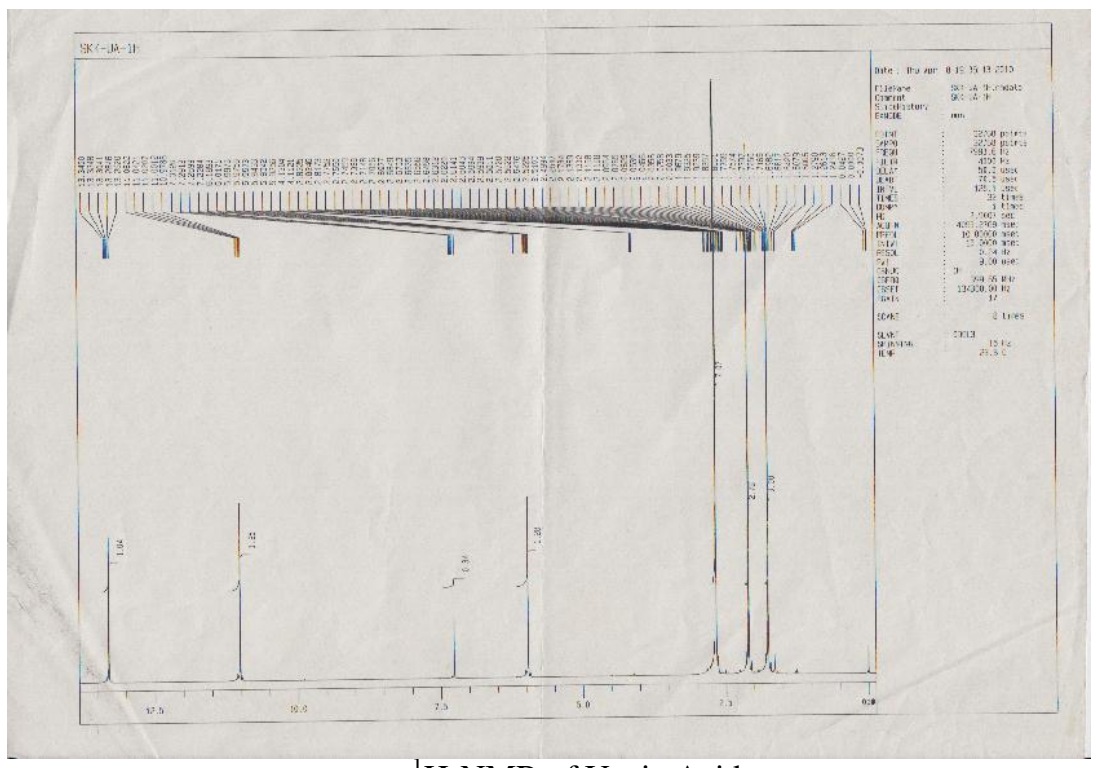

${ }^{\mathrm{l}} \mathrm{H}-\mathrm{NMR}$ of Usnic Acid

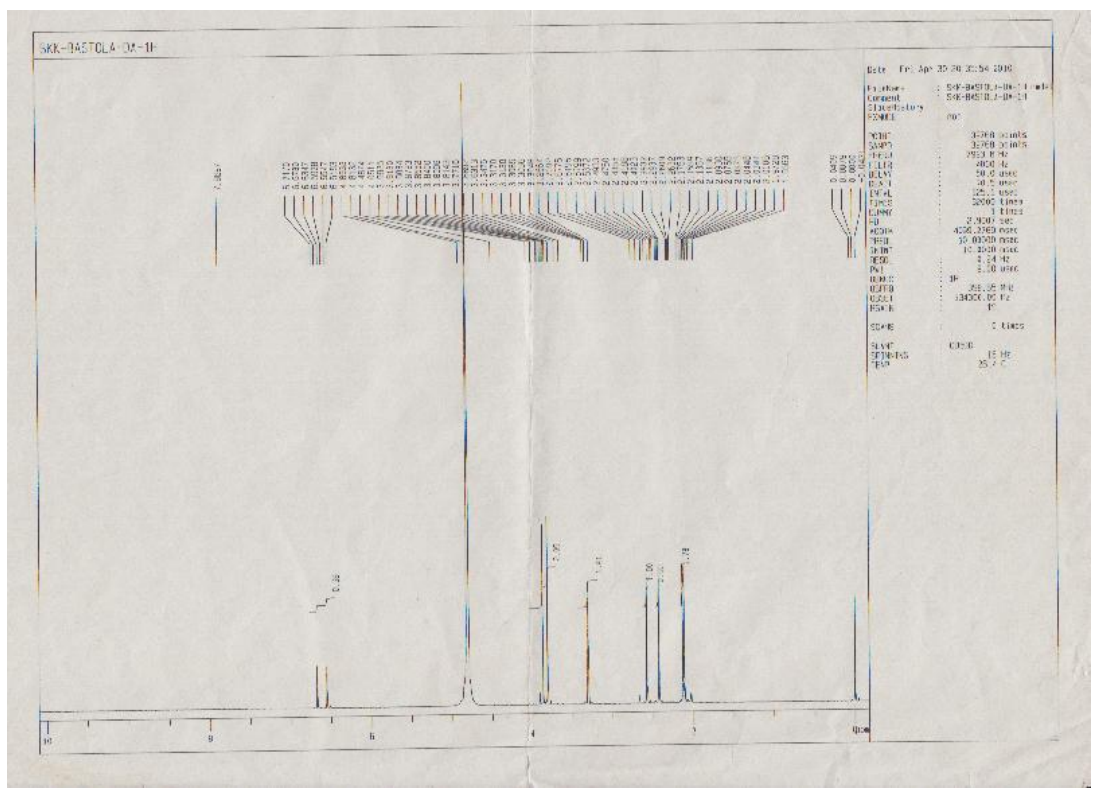

${ }^{1}$ H-NMR of Diffractaic Acid

From Brine Shrimp bioassay, the ethereal and methanolic extracts of Unsea orientalis were found to have $\mathrm{LC}_{50}$ value less than $1 \times 10^{3}$ and showed pharmacologically active. Methanolic extract of Rhododendron Campanulatum showed $\mathrm{LC}_{50}$ value less than $1 \times 10^{3}$ indicating more cytotoxic whereas 
EtOAc extract of Rhododedron campanulatum showed $\mathrm{LC}_{50}$ value more than $1 \times 10^{3}$ indicating less cytotoxic in nature.

From Screening of Antimicrobial activities test, the highest zone of inhibition (ZOI) was found in the ether extract of Usnea orientalis with diameter $17 \mathrm{~mm}$ for Staphylococcus aureus and lowest ZOI was seen in EtOAc extract of this lichen with $9 \mathrm{~mm}$ for $S$. typhii. The highest zone of inhibition (ZOI) of methanolic extract of Usnea orientalis was $12 \mathrm{~mm}$ for Staphylococcus aureus and lowest zone of inhibition (ZOI) was of each 10mm for Pseudomonas and Proteus vulgaris. Similarly, the highest ZOI was found in the Methanolic extract of Rhododedron campanulatum with diameter $25 \mathrm{~mm}$ for E.coli and lowest was seen in this plant with diameter $22 \mathrm{~mm}$ for Klebsiella spps. The zone of inhibition (ZOI) of usnic acid for gram positive bacteria $S$. aureus was found to be $18 \mathrm{~mm}$.

\section{Conclusion}

Four constituents usnic acid, diffractaic acid, atranorin and eumitrin from the ethereal extract of Usnea orientalis have been isolated and identified. Ethereal and methanolic extracts of Usnea Orientalis were found to have cytotoxic activity. Usnic acid and Diffractaic acid have found to cytotoxic activity. Methanolic extract of Rhododendron campanulatum showed more cytotoxic, whereas EtOAc extract of this plant showed less cytotoxic in nature. Antimicrobial activities studies showed the in ethereal extract of Usnea Orientalis against Staphylococcus aureus as the highest zone of inhabitation and methanol extract of Rhododendron Campanulatum showed the highest zone of inhabitation against E. coli.

\section{Acknowledgement}

The author is very much indebted to the Central Department of Chemistry, Kirtipur, Kathmandu, Nepal and wishes to thank to Toyama University of Japan for providing H-NMR spectra.

\section{References}

1. Yank Dun Mei, N. Takeda, Y. Litaka, L Sankawa, Tetrahendron, 29(3), 519-28(1973).

2. Hale, M.E. The biology of lichens,Second edition, p.160 and p.179

3. Sheak A. et. al, Lichen Resinoid of Commercial Importance from Nepal, a paper submittedto $11^{\text {th }}$ Internatonal Congress of essential oils, fragrance and flavours, new Delhi 1989

4. C.B. Biniya, The Floristic Composition of lichens in Sikles(Kaski) and Sivapure and their ecology,M.Sc.Dissertation submitted to Central Department of Botany, T.U.(1996).

5. Shrestha Suja, Phytochemical and biological study of Taxus Baccate and lichens, A Dissertation submitted to Central Department of Chemistry, T. U.(2001)

6. Dhar M.I., Neelkanthan S., Ramanujam S. and Seshadrei T.R.,J.Sci.Ind.Res.(India) 1959, 18B, 111-113.

7. Asahina Y. and Fuzikawa F.,Chem. Ber. 1932, 175-178.

8. Fernande O. and A, Pizzarrosa, Rev. Real. Acad. Criene. Exract. Fis. Nat, Madrid, 1958, 52, 557-563. 